\title{
6
}

\section{Consistent Identification and Traceability of Objects as an Enabler for Automation in the Steel Processing Industry}

\section{Helmut Zsifkovits, Johannes Kapeller, Hermann Reiter, Christian Weichbold and Manuel Woschank}

\subsection{Introduction}

An intelligent product in manufacturing systems is a physical product that can itself provide data for its own, virtual image in the manufacturing process (Kagermann et al. 2013). Thus, a basis is provided at all times

H. Zsifkovits $(\bowtie) \cdot$ M. Woschank

Chair of Industrial Logistics, Montanuniversitaet Leoben,

Leoben, Austria

e-mail: helmut.zsifkovits@unileoben.ac.at

M. Woschank

e-mail: manuel.woschank@unileoben.ac.at

J. Kapeller

Boston Consulting Group, Vienna, Austria

H. Reiter

ZKW Group, Wieselburg, Austria

C. Weichbold

Voestalpine Stahl Donawitz, Leoben, Austria

(C) The Author(s) 2020

D. T. Matt et al. (eds.), Industry 4.0 for SMEs, https://doi.org/10.1007/978-3-030-25425-4_6 
for reacting to the product-specific parameters during production, to initiate decentralized decisions and to identify areas for process optimization more easily. From the point of view of production plants, it is equally advantageous if the digital connection between the products and the actual plant enables intelligent automation of the processing steps. This requires permanent and real-time traceability of objects and their states.

Traceability is essential to gain knowledge of causes of deviations in product attributes, since it makes it possible to trace product deviations back to root causes within the production process. Further benefits from traceability include lot uniformity in production, and the reduction of the extent to which products are affected by product recalls. Traceability supports fact-based decision-making and continuous improvement (Kvarnström 2008).

Moreover, the issue of traceability is by no means only for the benefit of companies. There are a number of industries where there is a pronounced demand in this regard. In particular, in the aerospace, chemical, pharmaceutical, food, and automotive industries, the requirements are regulated in great detail. From the point of view of the end customer, safety must be guaranteed, all demands on quality must be complied with, and there should be a minimum of risk potential. From the point of view of the company, it is above all, a question of liability or, in the $\mathrm{B} 2 \mathrm{~B}$ area, the possibility of recourse between companies, i.e., the avoidance of economic business risk.

In the current ISO 9001, the international standard that sets out the criteria for a quality management system (QMS), the following requirements around identification and traceability are defined: "Use suitable means to identify outputs when it is necessary to ensure the conformity of products and services. Identify the status of outputs with respect to monitoring and measuring requirements throughout production and service provision. Control the unique identification of the outputs when traceability is a requirement, and retain documented information to enable traceability" (ISO 9001, 2015). Thus, these requirements can be broken down into three distinct elements: (i) output identification, (ii) process stage, and (iii) traceable identification.

Depending on the required level of traceability, various methods may be employed, from individual component unique stamping or bar 
coding to whole lot/batch identification, in combination with documenting information manually or electronically gathered from suppliers and during processing. This can be through part labels, job travelers, work orders, production plans, route sheets, process validation worksheets, lot/batch control, test certificates, "inspected" labels, or any means to identify outputs and their status.

Object identification and traceability provide the information required to enable five functional areas which, depending on the existing basic architecture, will be more or less developed or further developed in the company (Bischoff 2015).

- Data collection and processing: This includes the collection and evaluation of data on processes, quality, products, production facilities, employees, and their environment. For the virtual image of reality, IT-based data collection of customer, product, production, and usage data is essential. Data evaluations include the analysis of overall equipment effectiveness and big data analyses, with the focus on improving process and quality. By capturing and analytically analyzing the data, considerable efficiency gains can be tapped, which have not been fully utilized until now.

- Assistance systems: These aim to provide the employee with the necessary information as quickly and easily as possible, anytime, anywhere. They summarize all the technologies that support employees in carrying out their work so that they can concentrate on their core tasks. These are, in particular, technologies for providing information (e.g., visualization systems, mobile devices, tablets, data glasses). Especially with regard to the ever-increasing individualization of products with decreasing quantities, the companies that use them have a great opportunity to design value-added processes efficiently.

- Networking and integration: This includes integration between divisions and departments within a company (vertical integration) and also between different companies (horizontal integration). The goal of digital networking is to improve collaboration, coordination, and transparency across business units and along the supply chain.

- Decentralization and service orientation: Decentralization necessitates the modularization of products and processes, decentralized 
control and the change to service orientation. The goal is to make increasing complexity manageable, along with coordination, steering, ultimately, so that the decision can be decentralized.

- Self-organization and autonomy: Here technologies and processes that carry out an automatic data evaluation are summarized. Based on these results, the systems in the process, such as products and machines, are then to react independently. This should create a closed loop, which leads to a self-configuration and self-optimization of systems. The most important requirement is data analysis and data exchange in real time.

These functional areas provide the informational basis for advanced systems in the sense of Industry 4.0. We will further investigate approaches and technologies which enable identification and traceability in the sense described above. In applying these, there are major differences with regard to product types, production flow, environmental conditions, and industry.

In process industries, non-discrete products, continuous flow with no natural batches, reflux flows, mixing, and intermediate storages make it even more difficult to achieve a high level of traceability in continuous processes (Kvarnström 2008). We will investigate some of these challenges and possible solutions in a case study from the steel industry, specifically focusing on the requirements and restrictions of SMEs. It has to be kept in mind that SMEs are usually able to control only minor segments of the supply chain, so they are not in a position to make their approaches and solutions an obligation for their suppliers and/or customers. Thus, they have to go for pragmatic, easy-to-implement solutions which do not require immense investments of time and finance.

\subsection{Background and Literature Review of Identification and Traceability}

Kvarnström (2008) distinguishes the concepts of traceability, traceability systems and traceability methods. Traceability is managed by traceability systems (Moe 1998). A traceability system enables traceability 
in a process by combining process information with data covering the product flow throughout the process. The product flow data can be continuously recorded or modeled with different traceability methods, e.g., individual component stamping to whole lot/batch identification.

In this chapter, we will use identification as the wider, more general term encompassing these concepts. As the traceability method is very often a physical or electronic label or marker, we will refer to this as labeling. The labeling method is the process of applying labels of a certain kind, e.g., by printing, engraving, or laser marking.

\subsubsection{Labeling Type and Content}

For better understanding, the most widely used types of labeling are briefly explained below, even simple manual, non-electronic labels create a significant basis for the entire system in terms of the virtual representation of reality (Zsifkovits 2013). Normally, the tag contents are different and depending on the code type, more or less information may be included directly in the code. However, the information on a label on the product - no matter what type of code—can be enriched with a unique identification digitally with a variety of other information that results from the real processes. For example, using a standard bar code with limited content, the virtual image of the product could be enriched with additional, digital data, up to mapping the entire life cycle. In every process that manipulates or uses it, more data are captured and stored. Several of these types of labels were developed decades ago in the 1960s; they are still widely used, though.

Plain Text (OCR code): This is the use of a plain text, which can be read by human operators without technical aids. The information content is limited to the available area on the product. The OCR code (Optical Character Recognition) is meant to be easily readable by both machines and humans. There are two types of monospaced (fixedwidth) fonts, OCR-A and OCR-B. The OCR-A uses only the uppercase letters of the alphabet, numbers from 0 to 9, and some special characters. The OCR-B may also contain lowercase letters and other special characters (Schulte 2013). With the progress made in character 
recognition technology and software, virtually any typographic text can be converted, so the standard is not required and not widely used anymore.

1D Code: The 1D code is the widely known "zebra-striped" bar code. This code is the best known and most widely used for goods identification (e.g., the Global Trade Item Number Code (GTIN)). The code is a string of vertical, parallel bars (bars) with different widths and spaces (Koether 2014). This code can be read by scanners or industrial cameras, but the amount of data are quite limited. There are many different types of $1 \mathrm{D}$ codes with different information content. Numericonly bar codes store numbers only, while alphanumeric bar codes contain a combination of numbers and alphabetic characters (letters). The basic architecture of bar codes is shown in Fig. 6.1.

2D Code: According to the defined coding rule, a two-dimensional sequence of dark and light areas within a rectangle is printed. Due to this arrangement, a 2D code can store much more information on the same surface as a $1 \mathrm{D}$ code. This code can be read by machine using a scanner or industrial cameras. There are several types of codes, such as QR Code (Quick Response Code) or Data Matrix Code with different information content (Knuchel et al. 2011). These codes can be applied to a component by means of labels, lasers, or embossing methods. The numbers given for storage capacity in Table 6.1 indicate upper limits. As all these codes support variable-length data content, and different error correction levels can be defined, the capacity and symbol size may vary.

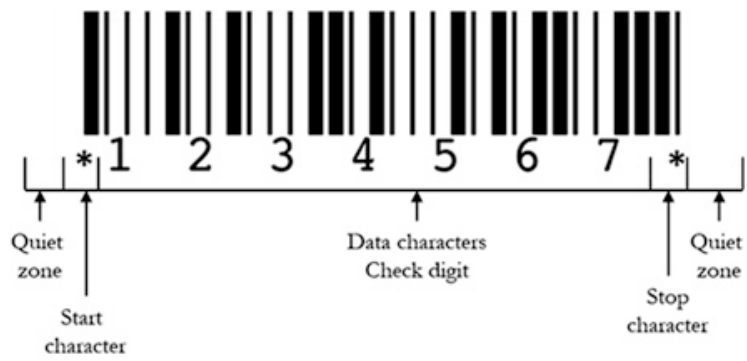

Fig. 6.1 Bar code structure (Source Adapted from Zsifkovits 2013) 


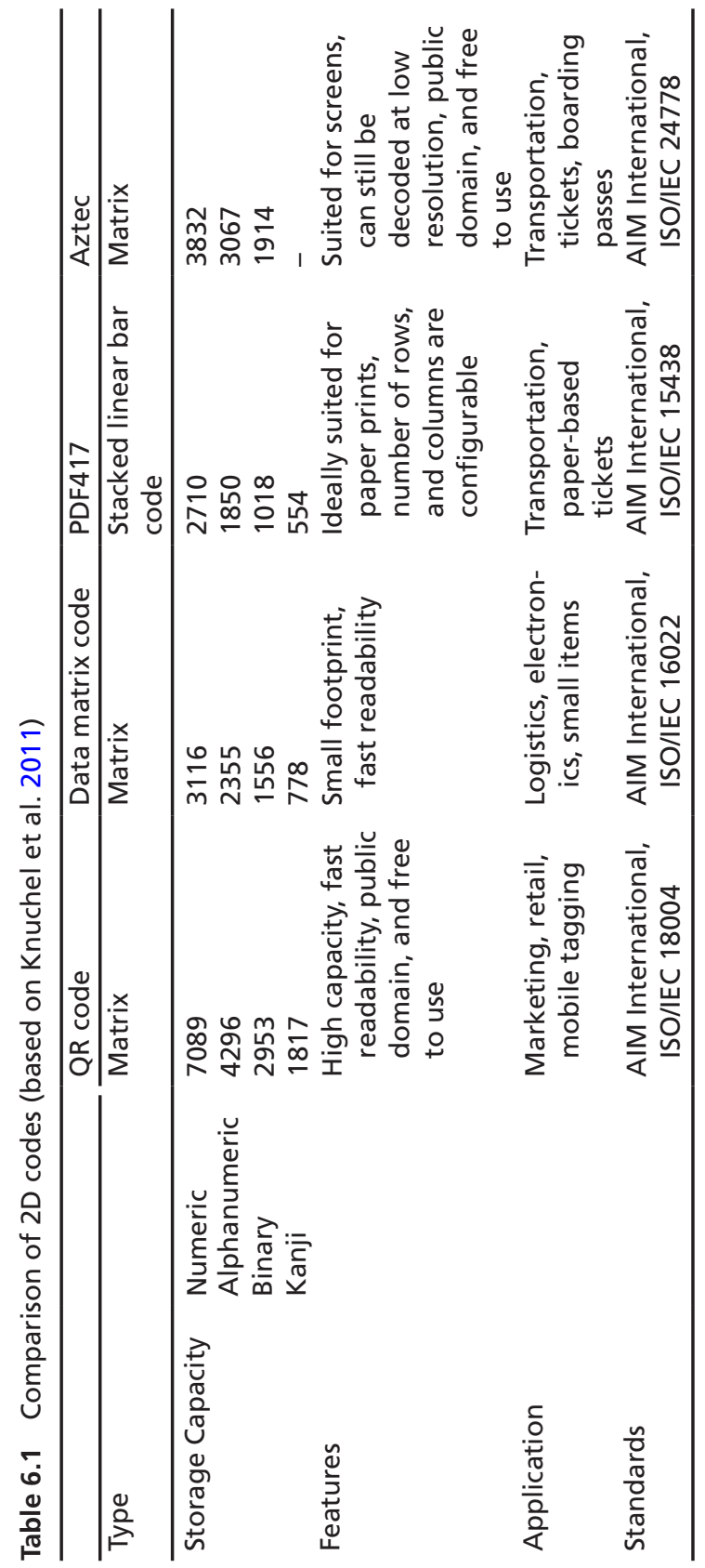


3D Code: There are some reports in the literature on the development of a 3D code (e.g., Microsoft Research 2007), but there is still no widespread industrial use. Here, by using the third dimension in the form of colors or depth information, the information content can be significantly increased. If a two-dimensional representation (e.g., QR Code) can encode the URL to a picture on the Internet, a 3D code can encode the picture itself. The storage capabilities are approximately 2000 binary bytes, or 3500 alphabetical characters per square inch in its highest density form, using eight colors (Microsoft Research 2007).

RFID: Radio-Frequency Identification tags come in many different shapes; depending on the area of application, they can be different in size, design, and also storage capacity. The storable amount of data depends on the available storage capacity on the RFID tag. RFID systems utilize radio waves and consist of three components: an RFID tag or smart label, an RFID reader, and an antenna. RFID tags contain an integrated circuit and an antenna, which are used to transmit data to the RFID reader which converts the radio waves and transfers data through a communications interface to a host computer system, where the data are stored in a database and analyzed. In contrast to bar codes that require that the scanner to maintain a line-of-sight with each code, RFID is a "near-field" technology, so the scanner only needs to be within the range of the tag to read it. RFID enables "Smart Logistics Zones" as a multiple-use concept of technical systems for identification, localization, and condition monitoring of different object levels in logistics and production processes (Kirch et al. 2017).

\subsubsection{Labeling Method}

For unique component identification, it is necessary that an identifiable code is used and the component itself is marked with a defined method. The method of labeling depends on the product, application, and the process requirements with regard to the application and environmental conditions.

In practical applications, many different labeling methods or specific marking methods can be found. In particular, in the marking process, it 
is important that on the selected surface, a mark of sufficient quality and accuracy is applied. This means that the requirements for contrast, dimensional accuracy of the attachment, edge sharpness of the marking, scratch resistance, wipe resistance, and other external influences must be met.

A distinction is made between direct and indirect labeling. In the case of direct marking, the marking is applied directly to the component, while the indirect marking uses another carrier unit for the information (e.g., printed label, RFID tag). This unit is in turn, connected to the component, usually by an adhesive technique. Often direct labeling is slightly worse in terms of quality of readability, especially if various surface treatments occur during production. Nevertheless, there are also a number of advantages (ten Hompel et al. 2008):

- Cost reduction is possible, no additional labels are needed.

- Code generation can be automated.

- The code is inextricably linked to the object.

Direct labeling methods include (Reiter 2017):

Mechanical engraving: By means of electric or pneumatic embossing units (needle embossing or needle scribing), among other things, plain text or $2 \mathrm{D}$ codes are applied directly to the surface of the component. Due to the deformation/depression on the surface, this marking method is also applicable to painting processes. However, there are signs of wear in the embossing units.

Laser marking: With the laser, many different characters, symbols, or codes can be applied to a wide variety of surfaces. It is a non-contact marking process in which the material to be inscribed is engraved by the impact of the laser (Müller 2008).

Electrolytic marking: An electrochemical etching process is well suited for applying clean, high-quality light/dark markings to metallic objects. A low-voltage current is passed through a stencil with lettering on the metallic object, thereby the lettering of the template is transferred to the object.

Inkjet printing: This non-contact process uses ink to apply the information. Depending on the field of application, different qualities can be realized. 


\subsection{Problem Formulation}

The labeling of a product makes a connection between the physical material flow and the associated information flow. The focus is on the real processes, the real product flows, and on the improved planning, control, and decision-making along the entire supply chain.

The focus of "digital" labeling is on real-time data generation during production and the continuous analysis of data with regard to a relevant impact on downstream production steps. Digital identification using a unique code and associated data contribute to increase material flow and product quality with a reduced effort to manually capture the state of products and machine tools. At the same time, a defined production sequence can be ensured in order to reduce process costs and avoid errors and defects. An error is an inadvertent mistake caused by a human/an operator, which can result in a defect. Thus, quality is produced the first time and is not "tested" in retrospect (Gerberich 2011). Moreover, this information provides improved traceability and root cause analysis in the event of an internal or external customer complaint.

Traceability can be defined from the perspective of the customer (upstream traceability) or from the processed product (downstream traceability) (Lichtenberger 2016). For upstream traceability, tracing starts from the customer who has received a product, either a final or intermediate product. In the event of a complaint, the product is used to check where the defective component is coming from or where this component was potentially installed. Downstream traceability applies a different view. A product is traced from a defective component through all stages of production. This also includes the customers who were supplied with the final product. The different views are shown in Fig. 6.2.

In most cases, current supply and production processes in industrial companies do not allow tracing of the product and process parameters at the level of the individual components and products. The parameters are only recorded either in isolated or highly aggregated form and are usually only available in batches. In case of serious customer complaints, the violation of security or quality of health standards, often 

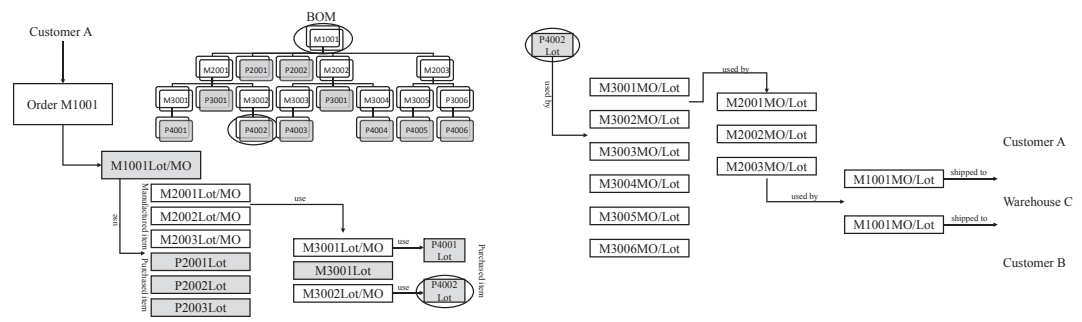

Fig. 6.2 Upstream and downstream traceability (Source Adapted from Yuan et al. 2011)

several thousand final products have to be recalled, as the affected production batch might contain a few defective or hazardous products. This in turn, could lead to high costs for repair, penalties, and compensation for enterprises throughout the entire supply chain.

Ultimately, noncompliance with quality requirements can lead to business-critical consequences, such as loss of competitiveness, reduced order intake, litigation due to quality problems, negative media coverage, and resulting loss in shareholder value.

The identification and the understanding of causal relationships in the production process, as well as the future reduction or avoidance of sources of error within industrial production processes thus represent an increasingly important factor for industrial companies as a basis for adaptive quality control.

\subsection{Methods/Methodology}

\subsubsection{Developing a Traceability Model}

To achieve digital transparency in a real production system and implement a generic concept, the following domains of the production system have to be taken into account and designed in detail (Reiter 2017):

1. Material flow: An analysis of the manufacturing process from the first delivery of the raw materials to the delivery of the finished products is required. In this context, it must be precisely defined when and where 
processes are performed, manually, by humans or fully automated by a plant. This applies in particular to transport, conveyance, and goods manipulation.

2. Production concept: Within the framework of production, it is important to understand whether entire batches or individual products "flow" through production. This allows the conditions for the generation of the digital image to be worked out. The delivery of goods may be a batch-oriented manipulation and mapping of the batch properties, whereby the properties apply to the entire quantity delivered. The actual unit (e.g., piece, liter, $\mathrm{kg}$ ) is of less importance. In the manufacturing steps, there may well be different requirements both on batch production and single-part production. Overall, it must be ensured that the reality of production with the associated production steps and the transport containers used is displayed digitally. This can be reflected in the form of a complete batch, a single container, or individual product.

3. Identification concept: The labeling method and content must be defined here. At the same time, the infrastructure must be provided for the generation of identification means (e.g., labels, RFID tags), as well as for the collection of static or dynamic information. In this context, it is very important that, in particular, direct types of marking, such as embossed data, are not damaged by the production steps or that their quality is not so impaired that automated identification during production is no longer possible. This decision must be made very early, as the marking should be made on a predefined part of the component. It is therefore advisable to consider this topic within the framework of the production and plant design.

4. Data model: When creating the data model, the requirements of the industry, the specific requirements of the customer, and the associated standards must be taken into account. Basically, two levels are relevant, static and dynamic information. Some examples for these are presented in Fig. 6.3 (based on Lichtenberger 2016):

- Static information: Data that form the general framework for production, such as the material number of a component, quantity, unit, parts lists and routings, drawings, inspection plans, measuring equipment, and their respective revision levels. 


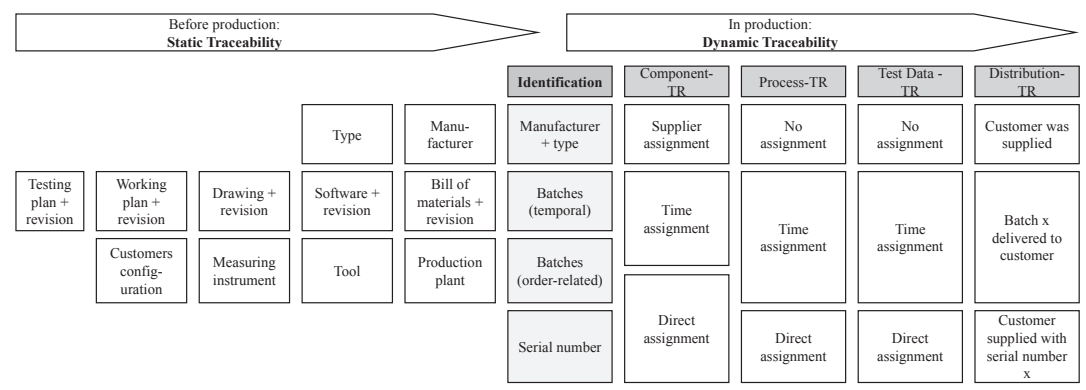

Fig. 6.3 Traceability before and within the production process (Lichtenberger 2016)

- Dynamic information: Data that are generated during series production or delivery to the customer and that can be assigned directly to a batch or a component, both in terms of time and content, such as the process data of a plant, results data of an inspection, or delivery information to a customer.

5. Identification and data generation: The interaction between static and dynamic information, as mentioned above, must be ensured. When generating data, the existing systems (e.g., ERP_Enterprise Resource Planning, MES_Manufacturing Execution Systems, PLM-Product Lifecycle Management) must be linked to each other, in accordance with the data model. This includes the use of markings on transport containers or individual products. Any manipulation of goods, any changes in product characteristics, or features must be recorded digitally. Depending on the manufacturing step, it can be a manual, partly, or fully automated process.

- Manual data generation: Product identification and data collection is done by humans, assisted by technical systems/devices such as scanners, to enable faster and error-free data capture.

- Fully automated data generation: In the case of technical production steps in a plant, a large number of process data are generated. These must be digitally connected in real time to the component. Therefore, an automated component identification has to be realized at the plant, and a connection to external systems is required. 


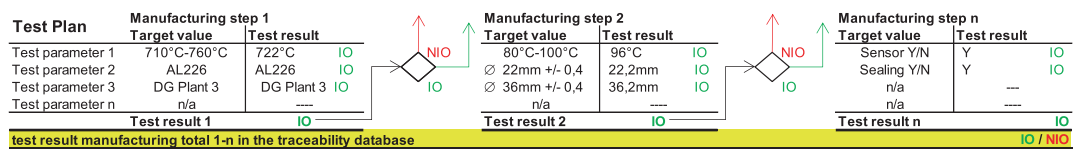

Fig. 6.4 Compressed view on traceability database (Reiter 2017)

6. Data analysis and real-time control: There are advanced and efficient technologies for data generation and storage, but the presence of data without context-oriented evaluation and interpretation does not represent any company-related added value. Therefore, it is necessary to process a high volume and large variety of data using models for filtering, aggregating, clustering, analyzing, and visualizing the results and, above all, providing them in real time at the place where they are needed. For this purpose, a traceability database with high availability can be used (see Fig. 6.4). Control can either be handled manually or by autonomous systems that react accordingly.

- Manual control: Care must be taken that the results for humans are presented in a simple, comprehensible, and transparent manner at the time of the demand. On this basis, the person either makes decisions or implements the proposed decisions (e.g., the check result is $\mathrm{NIO} /$ reject - parts are removed from the process, check result is $\mathrm{IO} /$ accept - parts are processed further).

- Automated control: The basic principle is the same as explained above; a system must react autonomously, though. In this context, it is important that the component is identified before the next value-adding manufacturing step begins to enable the review of the result of the upstream manufacturing step, so the system can react to it in real time. An example of the basic logic is shown below.

From the domains described above, a generic, hierarchical model for the implementation of digital product labeling is defined. The traceability model describes the relations between process steps, labeling type and method, information systems, and data. It aims to create a virtual image of business-related reality and permanent knowledge of quality-related 
parameters and results per batch or product to increase quality and reduce error costs.

\subsubsection{Traceability Issues in Process Industries}

Research literature on traceability is dominated by descriptions of traceability issues in parts production. In the flow of discrete components and products, various kinds of identification markers can be attached to a product or batch and followed, so traceability is usually high.

Process industries very often-at least in some stages of their supply chain-handle bulk material in continuous processes. In transport, a distinction is made between the two classes of goods - unit loads and bulk goods. Unit loads do not change shape during the transport process and can be handled individually. They are identifiable in terms of unit numbers and can be broken down into containers, bales, boxes, machine parts, etc., and their characteristics (dimensions, shape, mass, etc.). Bulk materials are defined as a variety of granular or dusty individual goods with relatively small dimensions, which have a low viscosity and change shape during the transport process. They cannot be formed into a single unit (unitized) without using containers. Bulk density, density, angle of repose, grain size, moisture content, etc., are physical properties of bulk materials (Martin 2014).

Continuous processes are processes where the products are refined gradually and with minimal interruptions through a series of operations (Fransoo and Rutten 1994). In industries using continuous processes, as are commonly found in the paper, food, mining, and steel industries, creating traceability implies major challenges that are rarely addressed in the literature (Kvarnström 2008). In some of these industries, such as mining, the traceability throughout the process from handling the raw materials to the final product is very limited.

Process flows in these industries can be serial, parallel, convergent, divergent, and reflux, often mixed with batch flows. The products are usually non-discrete; they change state and structure in the process, e.g., through chemical treatment or grinding (Fransoo and Rutten 1994). 
With an uninterrupted flow, there are no natural batches. In order to achieve a high level of traceability, there has to be a way to divide the product flow into traceable units, like lots or batches.

Reflux flows, mixing operations, and intermediate storages make traceability based on the order of appearance (first-in-first-out principle) often inappropriate.

The methods of material identification commonly used in production and transport chains are only applicable to unitized goods and partly to discretizable and unambiguously determinable bulk goods (Martin 1999).

In recent years, attempts have been made in various industries to track the inhomogeneous, continuous flow of goods through various technological approaches. For example, attempts have been made to detect the bulk material by introducing markers which have identical flow characteristics as the bulk material but at least one easily distinguishable feature (Hötger 2005). In order to achieve a reliable identification of the material, physical properties (color, magnetism, radioactivity), chemical parameters (tracers), or also auto-ID methods (codes, RFID) can be used.

We will address some of these issues in the following part, using the case of an international manufacturer of high-quality steel products.

\subsection{A Case-Tracing Continuous Flow in Process Industries}

The company focuses on the production and machining of steel bar products that are in the alloyed quality range, rolled or bright, pre-fabricated, surface-treated, or ready-to-install components. They are the basis for high-tech components, camshafts, steering gears, construction and agricultural machinery, diesel injection units, piston rods, and chain pins.

The products are used wherever components are subject to high levels of strain or it is essential that components function safely. They are machined with maximum precision and meet the tight tolerance requirements of extremely demanding sectors, like automotive, engine and plant construction, and specialist applications. 


\subsubsection{Initial Situation and Project Steps}

In the steel processing industry, initiatives toward digitalization and Industry 4.0 are commonly in quite a premature state. Research is limited and the potential applications still need to be researched. There is an awareness of potential gains in productivity, efficiency, flexibility, and competitiveness, though. A lack of competence in these areas, and the harsh conditions prevailing in the industrial environment, such as high dust and dirt levels, noise, and high temperatures, makes the situation more difficult.

In an industrial environment, each individual product or assembly, such as a threaded rod in an automobile, is identified by a specific serial number. In principle, this makes it easy for the end customer to reorder spare parts. However, the serial number is also used in the area of quality assurance in order to be able to initiate specific recall actions in the event of faulty products. Furthermore, by identifying a defective product, targeted process improvement initiatives can be launched within the company or throughout the supply chain. In most cases, the general conditions prevailing in the industry prevent a direct assignment of product defects to the associated product and process parameters. Serial numbers are only used for batch identification, so that traceability at the level of the individual products cannot be carried out.

Improved identification and traceability at the individual product level would be the basis for adaptive quality control and thus generate considerable potential for product and process improvement. In addition to significant cost savings within the supply chain, improved quality can also be achieved.

The project outlined here deals with the development of adaptive quality control based on the continuous identification and traceability of individual products within industrial production processes. This will enable an early detection and avoidance of production errors and defects by a continuous analysis of product and production parameters. We will give a brief overview of the basic processes relevant to the project.

Continuous casting (also called strand casting) is a process whereby molten steel is solidified into a billet (length of metal with a round or 
square cross section, 30-150 $\mathrm{mm}$ square), bloom (produced by a first pass of rolling, cross section $150-400 \mathrm{~mm}$ square), or slab (rectangular in cross section) for subsequent rolling in the finishing mills steel processing. These semi-finished casting products are first cut into sections, then are transferred to the rolling mill. Rolling is the process in which metal is passed through one or more pairs of rolls to reduce the thickness and make the thickness uniform. This results in elongation of the workpiece which is consequently cut into rods. These are then bundled, according to customer orders, to enable efficient loading and transport. The process investigated in the project starts with the receipt and storage of billets from various suppliers, before the rolling operation is performed.

In the first project phase, an evaluation of the state of the art of material identification systems was carried out, analyzing the prevailing conditions in the steel processing industry. In a material flow analysis, existing production processes and their interfaces were collected, visualized, and evaluated. Then, based on the knowledge gained, the model of adaptive quality control was developed. The product and process data generated at individual product level will be integrated into a centralized data management system, which still has to be designed and implemented.

The production data transmitted by the suppliers can only be partially used for quality assurance, due to the missing link with the products or with the production process of the processing company. There is also a break in the usage of media within the supply chain (customer, supplier). Data formats are inhomogeneous and incompatible; some information is passed on by paper or fax (see Fig. 6.5).

A synchronized information flow based on data standards would make it possible to retrieve product/production process data from faulty parts afterwards, e.g., temperature, composition, cycle times. The development of an adaptive, learning quality management system (see Fig. 6.6), becoming increasingly effective by constantly recording the data and feeding it into an analysis database, opens up much potential for improvement. 


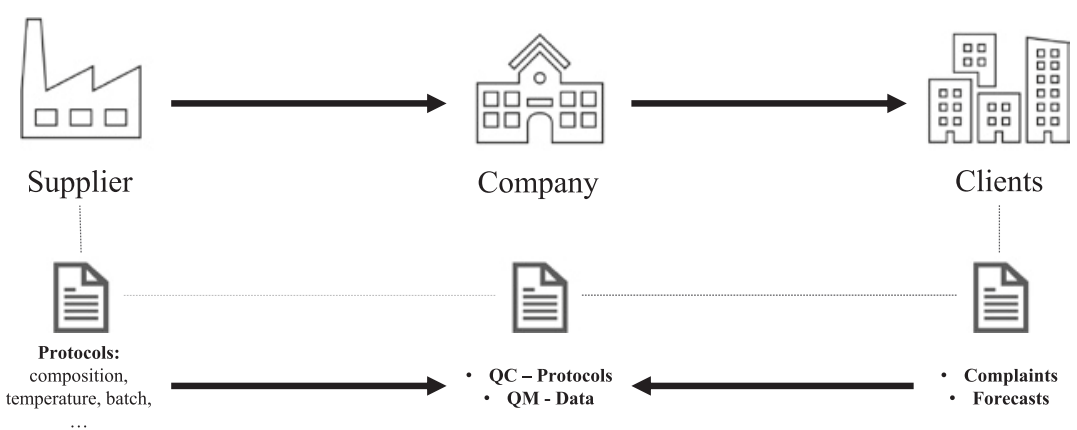

Fig. 6.5 Data flow in the supply chain

As a first step in the project, a process survey for rolling mill/heat treatment was carried out. The physical separation of the input material for the areas of rolling, continuous annealing (conventional heat treatment), and inductive annealing (inductive heat treatment) was documented in a process diagram.

Next, the process survey of the bright steel division was carried out. The analysis concentrated on the areas of peeling, straightening, and testing. In the course of this process survey, it became obvious that there is a risk of mixing products classified as "accept/IO" and "reject/NIO" during separation, sampling, and post-processing (e.g., the hardening process). The findings of this survey were also illustrated in a process diagram.

All the critical transition points and interfaces in the rolling mill process were identified. For full traceability of the manufactured products, a continuous identification in the rolling mill process was required. For this reason, special attention was paid to these processes during the concept generation. The bright steel, with a more linear sequence of process steps, appeared to be less challenging.

Consequently, alternative solutions for identification and traceability were conceived (concepts I to III, and eventually concept IV). These proposals are the result of the process survey, the restrictions identified through this survey, and the discussion with the people involved in the process. 


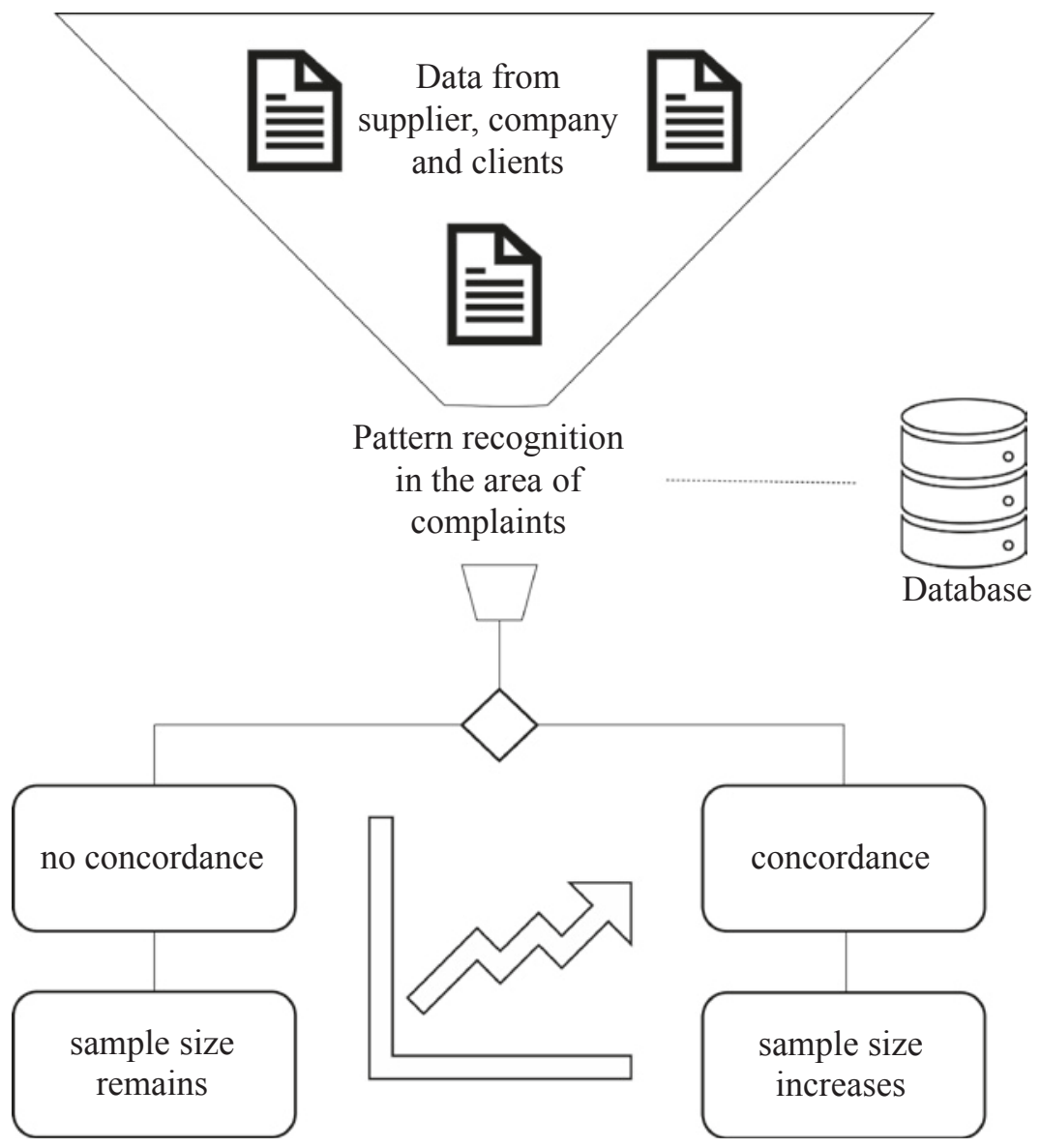

Fig. 6.6 Adaptive quality control

\subsubsection{Evaluation of Proposed Solutions}

Concept I comprises identification at rod level and uses a combination of bar code, laser marking, and inkjet print on paper.

One way of identifying individual rods is to mark them with heat-resistant bar codes. Seven codes per section are applied or sprayed longitudinally during transport of the rolled wire sections. Matching the conveyor speed with spray unit operations is required for the precise 
spacing of the codes, so that after another separation, each rod is provided with a bar code. The marking by a spray head is done between the separation of the rolling strands and the cooling process.

As it is possible, and probable, that several billets will be mixed during the formation of a bundle after the separation of the rolling strand sections, it is necessary to apply the markings at this stage. The presence of a spray head, which can apply bar codes generated by a system using heat-resistant paint, is necessary for the implementation of this variant. When the rods are combined to form bundles of approx. five tons of weight, the rods can come from up to ten different strands and, as a result, from up to four different billets. Therefore, it would be possible to assign the individual rods of a bundle to the source billets with only four different bar codes. However, in order to obtain a unique identification at rod level, each rod is marked with a unique code.

Due to the heat-resistant marking, this can be maintained until before the peeling process. After the inductive heat treatment, the code must be scanned, and converted into a QR code which points to the source billet and is applied frontally at both ends of each rod by a laser (face marker). As shown in the following graph, this takes place between the inductive heat treatment and the peeling process:

Before the next cutting process, in which the ends of the rods are removed, the face marker is scanned. All information on the individual rods can now be stored on a standard bar code which is applied to the finished product using an inkjet process. Concept I is illustrated in Fig. 6.7.

Concept II comprises identification at billet level and uses a combination of color coding, laser marking, and inkjet print on paper.

Another option for providing traceability in this process is a combination of color and laser marking, or a combination of color marking and embossing. Color codes are applied after strand separation ("flying shears") and a laser engraving (bar code, QR code) is applied on the front side in the material storage area.

From the survey carried out in the area of the flying shears, a color coding using two colors came out as a possible solution. This can be justified by the fact that for the product under consideration five-ton bundles are produced after the hot separation line. Based on the data, these 

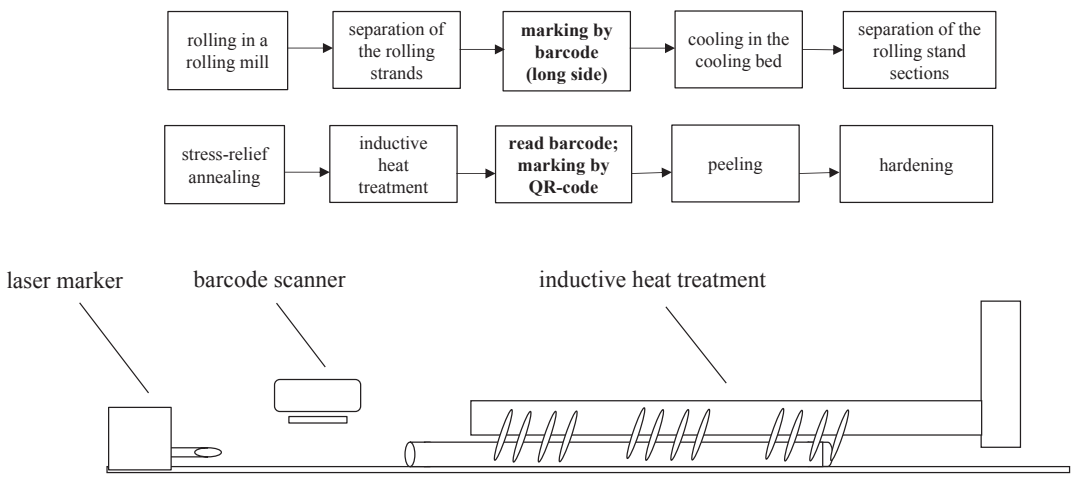

Fig. 6.7 Concept I-bar code and laser marker

bundles consisted of about 400 rods, which corresponds to an approximate number of ten strands or four billets. Therefore, a positive identification of source billets can be achieved by the use of two colors and the permutations possible.

For the further and/or continuous identification in the course of this concept, a separation of the bundles at the new interface (material storage location) is planned. The bundles are opened after arrival and fed to a separating machine.

This machine is equipped with optical recognition which identifies and systemically assigns the respective billets on the basis of the color coding. After the identification has been carried out, a laser engraver or embossing tool is used to apply a unique identification to the front side of the material. In addition to storing relevant data, this allows the sections to be numbered consecutively, so their traceability is clearly guaranteed. The advantage of this procedure is that it ensures identification despite any environmental influences (surface scale, heat). In order to implement this concept, it is not necessary to make any major changes to the existing process, since the frontal marking is retained until the last step of the bright steel process, the separation. After this step, the finished individual rods can be marked for the end customer using inkjet or paper labeling (see Fig. 6.8). 


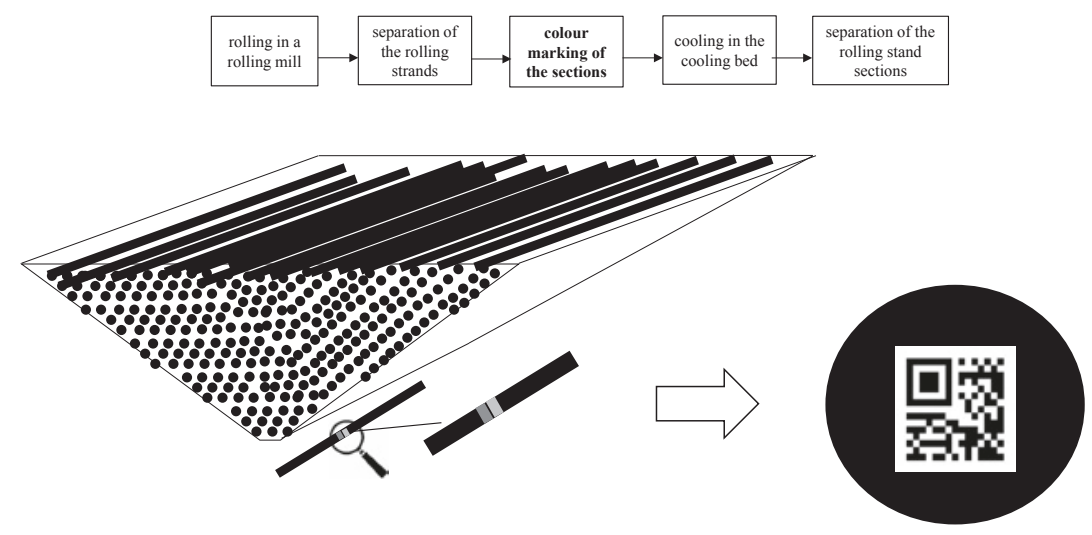

Fig. 6.8 Concept II—color marking

Concept III comprises identification at rod level. This requires a structural modification of the cooling bed and uses laser marking.

This solution aims to prevent the mixing of consecutive rolling strand sections, and requires a physical modification in the production line, between the flying shears and the hot cutting line. A low barrier will prevent the mixing of several rolling strands directly after cutting them to length with the flying shears.

This structural modification, would prevent the mixing of several rolling strand sections. The process-related sequence would ensure a clear allocation of the sections up to the area of the hot separation line. Another modification has to be made in the cooling bed itself. A part of the cooling bed is separated from the rest of the cooling bed by means of a movable cut-off plate, thus ensuring an equal supply to the hot separation line. Hydraulically/pneumatically retractable spacers also ensure the distance between the respective rolling strand sections. The precise positioning of rods also serves the further process step of frontal marking. During the cutting process, the products can be marked on the front by means of laser markers or embossing. By preventing sequence mixing, an unambiguous marking for each individual rod can be guaranteed and assigned to the sequence stored in the work plan. 
In order to implement this concept, it is not necessary to make any major changes to the existing process, since the frontal marking is retained until the last step of the bright steel process, the cutting of the rod ends. After this step, the finished individual rods can be marked for the end customer using inkjet or paper labeling. Concept III is illustrated in Fig. 6.9.

The proposed alternative solutions were further evaluated in terms of costs, reliability, and their impact on processes and cycle times. Potential problems were considered, due to environmental influences (surface scaling, mechanical stress, temperature, etc.). The major advantages and disadvantages of the three concepts and some remarks from the discussion are summarized in the following Table 6.2.

The possible problems and barriers to implementation of the previously described concepts resulted in the development of yet another concept, concept IV. The critical interface of the hot separation line resulting from the process evaluation formed the starting point of this concept.

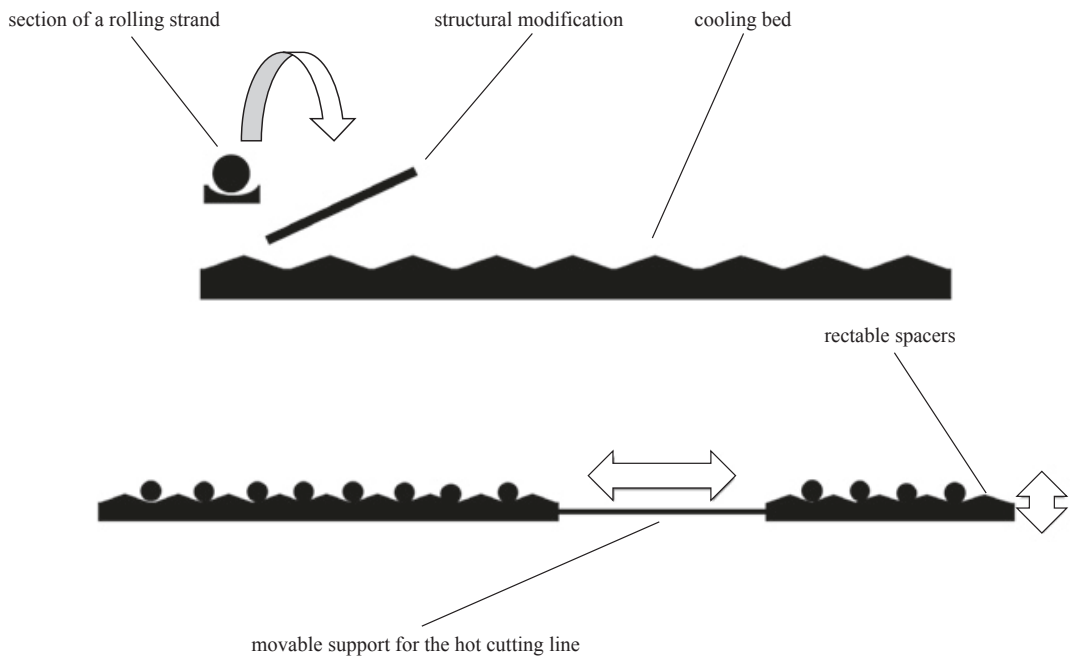

Fig. 6.9 Concept III-modification of the cooling bed 


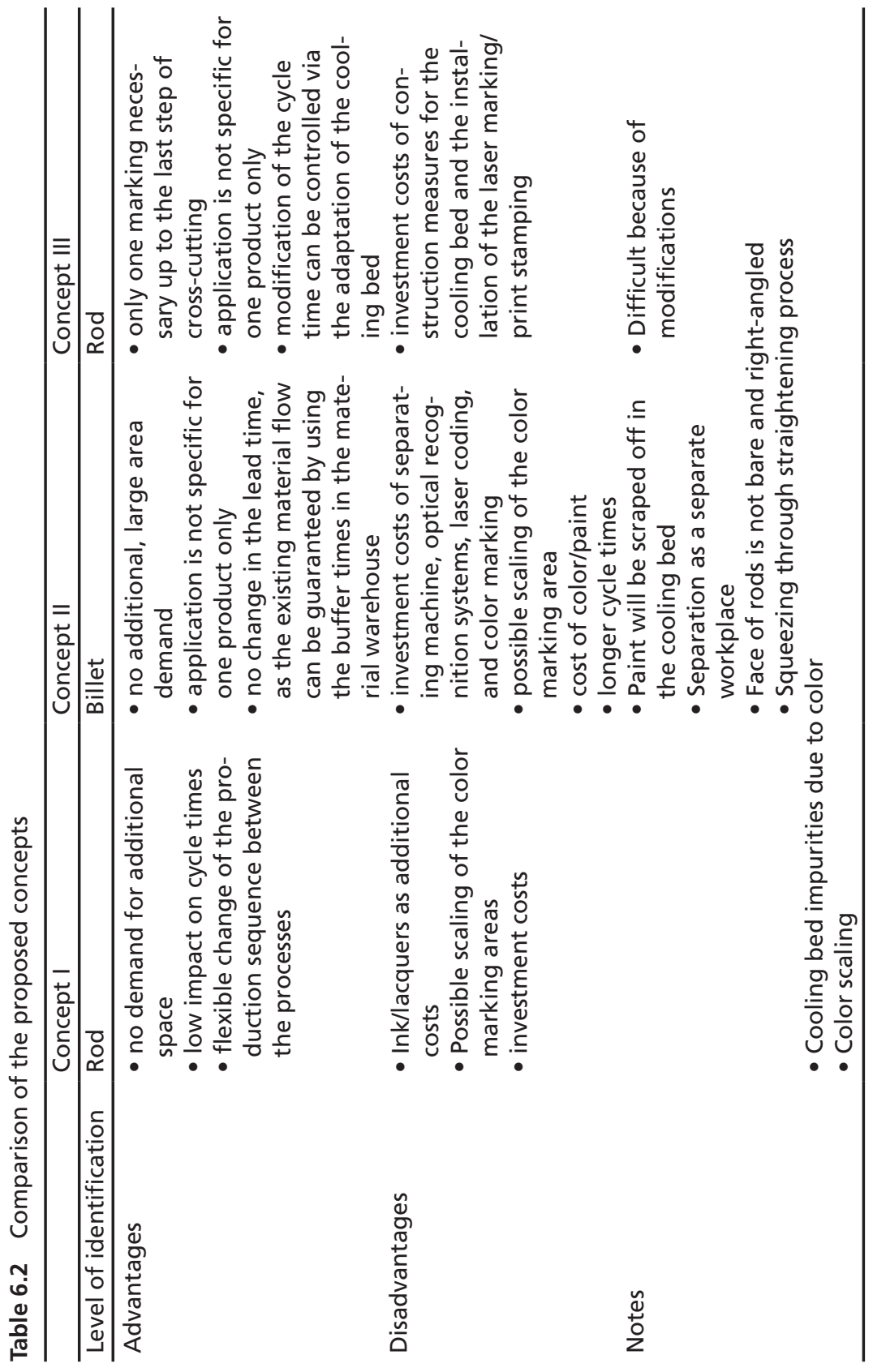




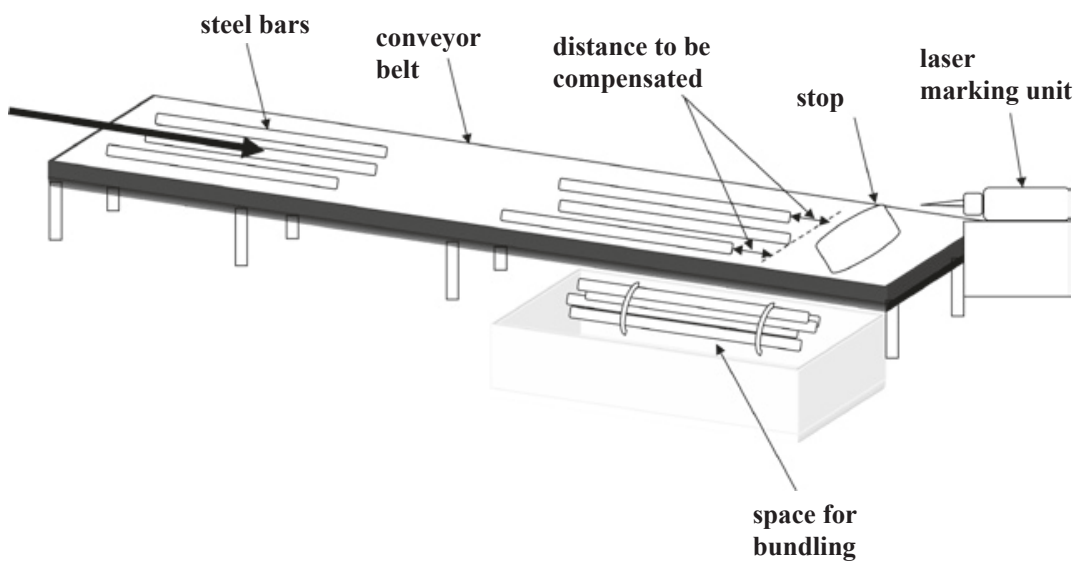

Fig. 6.10 Concept IV—Schematic illustration

This concept is based on the idea of an unambiguous identification of the individual rods through the production sequences stored in the work plan by means of a laser marking device. A mixing of the bars at the cooling bed could only occur in case of a malfunction, so a structural modification was not considered necessary. The workplace for laser marking and bundling has to be redesigned, though. Some of the advantages and limitations of the other concepts are avoided, like scaling. There is no negative impact on cycle times. Investment costs for the marking and bundling workplace are higher, though.

The project partners agreed to test this identification solution under real conditions. This pilot testing was carried out after a market analysis and led to positive results, which further underlined the feasibility of the project. It became clear that several marking devices or laser markers had to be purchased for successful implementation. It also became obvious that a structural modification of the hot cut-off line outlet in the form of a mechanical barrier (stop) was necessary, which, however, did not cause any reduction in cycle time. Concept IV is illustrated in Fig. 6.10.

Further feasibility checks will be carried out, and it will also be clearly established that there is a need for Level II automation for the successful implementation of this project. Level II automation is considered a 
further step toward Industry 4.0, with an increased ability to react on product-specific parameters during the manufacturing process, to enable autonomous, decentralized decisions at the level of machines and production lines, and to identify areas for process optimization more easily.

\subsection{Discussion and Conclusions}

The preceding chapter discussed features of intelligent products, machines, and facilities in manufacturing and logistics systems, as objects that are able to provide data for their own, virtual image. Thus, "digital twins" can be established, of products and process flows, to be used for planning and control of the plant. The digital connection between the products and the actual plant enables intelligent automation of the processing steps, and smart. This requires permanent and real-time traceability of objects and their states.

Traceability makes it possible to better control processes and trace product deviations back to root causes within the production process. Improved uniformity in production, and the reduction of product recalls can be named as further benefits from traceability of lots. In a number of industries, such as the aerospace, chemical, pharmaceutical, food, and automotive industries, there is a pronounced demand for traceability. The requirements are regulated in legislation, standards, guidelines, and common practices, to hold paramount the safety and wellbeing of consumers and users of the product, to ensure high levels of quality, and to reduce risk.

To ensure traceability, a structured approach should be used, taking into regard the systems and processes in material flow, production, and identification, and establishing systems and technologies required for data storage, identification and data generation, and data analysis and real-time control.

For object identification, labels and markers of various types (e.g., bar codes, 2D codes) are used, applied with different methods (e.g., print, electronic tags). Digital labeling provides real-time data generation 
during production and the continuous analysis of data, using unique codes for unambiguous identification of products and their states.

The methods of identification widely used are mostly only feasible for discrete, unitized goods. Many industrial processes, in food processing, paper mills, mining, and steel industries, in contrast, handle bulk material in continuous processes. These materials cannot be unitized, and made identifiable without using containers. Attempts have been made in various industries to track the inhomogeneous, continuous flow of goods through various technological approaches, e.g., introducing markers into the material, or using physical properties, chemical tracers, or auto-ID methods (codes, RFID).

We discussed the problems in product identification and traceability in these processes, and the potential application of methods and standards established in discrete processes. The case of a steel processing company served to illustrate the challenges involved, and how to develop alternative solutions.

Further efforts, both in research and application areas, will be needed to develop effective identification and traceability in these critical sectors of industry and supply chains. Also, standardization and legislation have to keep up with new technologies, their opportunities, and risks. Non-discrete products represent a considerable share of all the products created, especially in the early stages of their value chain. Being able to better control their flow and quality will open up opportunities for improved effectiveness and efficiency in the way we produce and handle products, and for more sustainable operations and material flows.

\section{References}

Bischoff, J. 2015. Erschließen der Potenziale der Anwendung von ,Industrie 4.0“ im Mittelstand. Studie im Auftrag des Bundesministeriums für Wirtschaft und Energie (BMWi). Mühlheim an der Ruhr: agiplan GmbH.

Fransoo, J.C., and Rutten, W.G.M.M. 1994. A Typology of Production Control Situations in Process Industries. International Journal of Operations \& Production Management 14 (12): 47-57. https://doi.org/10.1108/ 01443579410072382. 
Gerberich, T. 2011. Lean oder MES in der Automobilzulieferindustrie: Ein Vorgehensmodell zur fallspezifischen Auswahl. Wiesbaden: Gabler. https://doi. org/10.1007/978-3-8349-6754-1.

Hötger, G. 2005. Verfahren zur Kennzeichnung von Schüttgut, derart gekennzeichnetes Schüttgut, sowie Verwendung von Lebens- oder Futtermittel für ein derartiges Schüttgut. Münster: Habbel \& Habbel.

ISO. ISO 9001:2015 Quality Management Systems-Requirements.

Kagermann, H., W. Wahlster, and J. Helbig. 2013. Umsetzungsempfehlungen für das Zukunftsprojekt Industrie 4.0: Abschlussbericht des Arbeitskreises Industrie 4.0. München: acatech - Deutsche Akademie der Technikwissenschaften e.V.

Kirch, M., O. Poenicke, and K. Richter. 2017. FID in Logistics and ProductionApplications, Research and Visions for Smart Logistics Zones. Procedia Engineering 178: 526-533. https://doi.org/10.1016/j.proeng.2017.01.101.

Knuchel, T., T. Kuntner, E.C. Pataki, and A. Back. 2011. 2D-Codes: Technology and Application. Business \& Information Systems Engineering 3 (1): 45-48. https://doi.org/10.1007/s12599-010-0139-z.

Koether, R. 2014. Distributionslogistik: Effiziente Absicherung der Lieferfähigkeit (2. Aufl.). Wiesbaden: Springer Gabler.

Kvarnström, B. 2008. Traceability Methods for Continuous Processes. Luleå: Luleå University of Technology.

Lichtenberger, S. 2016. Entwicklung eines Modells zur Darstellung von Traceabilitydaten in Abhängigkeit von Traceabilityanwendungsfällen.

Martin, H. 1999. Praxiswissen Materialfußplanung. Wiesbaden: Vieweg + Teubner Verlag. https://doi.org/10.1007/978-3-322-96885-2.

Martin, H. 2014. Transport- und Lagerlogistik. Wiesbaden: Springer Fachmedien Wiesbaden. https://doi.org/10.1007/978-3-658-03143-5.

Microsoft Research. 2007. High Capacity Color Barcode Technology. https:// www.microsoft.com/en-us/research/project/high-capacity-color-barcodes-hccb/. Accessed on April 15, 2019.

Moe, T. 1998. Perspectives on Traceability in Food Manufacture. Trends in Food Science \& Technology 9 (5): 211-214. https://doi.org/10.1016/S09242244(98)00037-5.

Müller, H. 2008. Markieren mit dem Laser: Ein schnelles, automatisierbares und robustes Verfahren. Laser Technik Journal 5 (2): 45-47. https://doi. org/10.1002/latj.200890008.

Reiter, H. 2017. Anwendungsmöglichkeit digitaler Produktkennzeichnung zur Erhöhung der Qualität am Beispiel der Automobilzuliefererindustrie. 
Schulte, C. 2013. Logistik: Wege zur Optimierung der Supply chain (6. Aufl.). München: Vahlen.

ten Hompel, M., H. Büchter, and U. Franzke. 2008. Identifikationssysteme und Automatisierung. Berlin, Heidelberg: Springer.

Yuan, M., H. Yeh, and G. Lu. 2011. The Development of Products Traceability for Enterprise Resource Planning System. 2018 IEEE 18th International Conference on Industrial Engineering and Engineering Management, 475-479. https://doi.org/10.1109/ICIEEM.2011.6035203. Zsifkovits, H.E. 2013. Logistik. Konstanz: UVK.

Open Access This chapter is licensed under the terms of the Creative Commons Attribution 4.0 International License (http://creativecommons. org/licenses/by/4.0/), which permits use, sharing, adaptation, distribution and reproduction in any medium or format, as long as you give appropriate credit to the original author(s) and the source, provide a link to the Creative Commons license and indicate if changes were made.

The images or other third party material in this chapter are included in the chapter's Creative Commons license, unless indicated otherwise in a credit line to the material. If material is not included in the chapter's Creative Commons license and your intended use is not permitted by statutory regulation or exceeds the permitted use, you will need to obtain permission directly from the copyright holder.

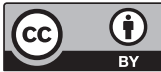

